\title{
Deformation Measurement of Glass Structure Using FBG Sensor
}

\author{
Bin $\mathrm{LIU}^{1 *}$, Shihai ZHANG ${ }^{2}$, and Jianping $\mathrm{HE}^{3}$ \\ ${ }^{1}$ School of Electronic and Electrical Engineering, Nanyang Institute of Technology, Nanyang 473001, China \\ ${ }^{2}$ School of Civil Engineering, Nanyang Institute of Technology, Nanyang 473001, China \\ ${ }^{3}$ School of Civil Engineering, Dalian University of Technology, Dalian 116024, China \\ ${ }^{*}$ Corresponding author: Bin LIU_ E-mail: liubin_ny@126.com
}

\begin{abstract}
Glass has been widely used as an important component in structures such as reflection glass curtainwalls, high speed trains, and landscape glass bridges with advantages of transparent and easy to clean, which are exposed to extreme weather conditions and external loads. Over time, these factors can lead to a damage of glass. So the health status of glass structure is critical, which should be routinely monitored to improve safety and provide reliable maintenance strategy. In this paper, fiber Bragg grating (FBG) sensors are used to monitor glass damage based on the fact that the main components of both the optical fiber and the glass are silica, which hints that both optical fiber and glass have the similar mechanical properties. Furthermore, the diameter of FBG installed on the glass structure is small, which has little effect on the beauty of glass. In order to validate the feasibility of the damage monitoring method, one common glass panel model with two-side fixations is loaded impact and static loads respectively, on the upper and lower surfaces of which four FBG sensors and two resistance strain gages are installed. A comparison study among the measured strains from the FBG sensors, those from the resistance strain gages, and those calculated from finite element model (FEM) analysis is conducted and the result obtained with experiments agrees with the element result. Test results show that the FBG sensors can effectively measure the glass deformation or damage under the impact and static load.
\end{abstract}

Keywords: FBG sensor; deformation measurement; glass structure; safety monitoring

Citation: Bin LIU, Shihai ZHANG, and Jianping HE, "Deformation Measurement of Glass Structure Using FBG Sensor," Photonic Sensors, 2019, 9(4): 367-375.

\section{Introduction}

Common glass whose main component is silicon has the advantages of transparent, beauty, and easy to clean. In order to enlarge its application fields, the toughened glass with high impact strength, the bullet-proof glass, and some other coloured glass have been produced and used extensively in industries [1]. For examples, the reflection glass curtainwalls have been widely used in China in the past 30 years: the area of reflection glass curtainwall soared to 200 million square meters; meanwhile, with the development of science and technology, more and more advanced vehicles such as sports cars and high speed trains are produced, and the windshields with large area are installed in these structures. In order to attract tourists, many landscape glass bridges such as Skywalk Glass

Received: 1 September 2018 / Revised: 21 November 2018

(C) The Author(s) 2019. This article is published with open access at Springerlink.com

DOI: $10.1007 / \mathrm{s} 13320-019-0534-0$

Article type: Regular 
Bridge in Canada, Grand Canyon Skywalk in USA, and Zhangjiajie Glass Bridge in China have been built in the world, the bridge decks of which are some high strength special transparent glasses. All these structures are exposed to extreme weather conditions and external loads such as wind load, pedestrian load, and vibratory load caused by the earthquake. Over time, these adverse factors can cause structural distress decreasing the capacity of the structure to sustain the designed loads. Once the structure fails, it will lead to serious accidents. For example, crack often appears in the curtain wall glass and the windshield caused by thermal load or local impact load, which may cause the glass broken finally. So the health status of glass structures is very critical, and the glass structures should be routinely monitored to improve safety, lower the risk of large damage, and provide reliable maintenance strategy [2].

At present, many studies about the windshield and glass curtain wall have focused on the blasting design and improvement of mechanic characteristics. The test methods for the glass, in general, use the material testing machine to study the mechanic characteristics in the lab, on the surface of which some electric resistance strain gauges are installed to record the strain data [3-6]. In the field applications, the manual detection method is usually provided to detect glass damage and evaluate its safety state regularly, but it has the shortcomings of poor real-time performance and high labor cost. Furthermore, the acoustic emission monitoring method has been used to monitor the damage of glass/epoxy composites, which can identify the crack of the structure [7]. Glass has a smooth surface and the characteristics of beauty and transparency, so ordinary force or strain sensors such as resistance strain gages can't be laid on the surface of the glass for a long time which also may affect its appearance. The fiber Bragg grating (FBG) sensor has several inherent advantages over conventional electrical sensors such as non-conductivity, resistance to corrosion, and immunity to electromagnetic interference. Because of these merits, FBG sensors have become one of promising sensing technologies for structural health monitoring and been widely used in the subgrade, bridge, and tunnel and so on [8-11]. Huang et al. used a 3D (three-dimensional) glass fiber-reinforced polymer packaged fiber Bragg grating sensor to construct a vehicle classification system [12]. Zhou and $\mathrm{He}$ also used glass fiber-reinforced polymer to package optical fiber to develop a novel distributed Brillouin strain sensor [13]. In the two studies, the main idea is that the size of the bare FBG or the optical fiber is small and the mechanical of the FBG or optical fiber is similar to that of the glass fiber-reinforced polymer, which ensures the correct sensing properties of the packaged sensors. The glass and optical fiber also have the similar mechanical properties for the reason that the main component of glass and optical fiber is silica. Meanwhile, the FBG has a small size (the diameter is about $0.125 \mathrm{~mm}$ ), which is installed on the glass surface and has little effect on the appearance or beauty of glass. These merits ensure that the FBG sensor can easily be installed on the glass, which correctly monitors the glass deformation without affecting glass's normal function.

In this paper, an FBG sensor is used to monitor the glass damage. In order to validate the feasibility and effectiveness of the damage or deformation monitoring method, one model test for a common glass panel with two-side fixations is conducted. The glass panel is loaded static and impact loads respectively, and four FBG sensors and two resistance strain gages are installed on the central position of the upper and lower surfaces of the glass panel. A comparison study among the measured strain from the FBG sensors, those from the resistance strain gages, and those calculated from FEM analysis is conducted.

\section{Strain and temperature characteristics of FBG glued on glass plate}

FBG is a type of distributed Bragg reflector constructed in a short segment of optical fiber written by powerful ultraviolet radiation, which has 
become one of promising sensing technologies for strain and temperature measurement in different structures. The specific characteristic of FBG for sensing is that their periodicity causes them to act as wavelength sensitive reflectors as

$$
\lambda_{B}=2 n_{e} \Lambda
$$

where $n_{e}$ is the effective refractive index of the optical fiber, and $\Lambda$ is the grating period [14].

Usually, the FBG is deformed due to the external load or temperature, which leads to a change in the grating period, followed by a change in the Bragg wavelength. Based on this physical property, FBG sensors respond both strain and temperature, and the Bragg wavelength's shift can be calculated by strain and temperature expressed as

$$
\Delta \lambda_{B}=C_{\varepsilon} \Delta \varepsilon+C_{T} \Delta T
$$

where $\Delta \lambda_{B}$ is the Bragg wavelength's shift, $C_{\varepsilon}$ and $C_{T}$ are the strain and temperature sensing coefficients respectively, and $\Delta \varepsilon$ and $\Delta T$ are the strain's and temperature's shift, respectively. For the bare FBG, the strain and temperature sensing coefficients are $1.20 \mathrm{pm} / \mu \varepsilon$ and $10.08 \mathrm{pm} /{ }^{\circ} \mathrm{C}$, respectively [15].

Silica is the major constituent of the common glass and the bare FBG, so the common glass and the bare FBG have the similar coefficients of thermal expansion. In order to validate the point, one strain and one temperature calibration tests are conducted. In the temperature test, two bare FBGs, named as TFBG1 and TFBG2, are installed on the surface of one common glass plate with the size of $100 \mathrm{~mm} \times 30 \mathrm{~mm} \times 7 \mathrm{~mm}$ by using epoxy resin adhesive, and the initial wavelengths of TBFG1 and TFBG2 are $1550.35 \mathrm{~nm}$ and $1554.290 \mathrm{~nm}$, respectively. One temperature control box is used to study the temperature characteristic of TFBG sensors, and the temperature changes from $40^{\circ} \mathrm{C}$ to $120{ }^{\circ} \mathrm{C}$. Figure $1(\mathrm{a})$ shows that the temperature sensing coefficients $\left(C_{T 1}\right.$ and $\left.C_{T 2}\right)$ of TFBG1 and TFBG2 are $10.33 \mathrm{pm} /{ }^{\circ} \mathrm{C}$ and $10.17 \mathrm{pm} /{ }^{\circ} \mathrm{C}$, respectively, which are approximately equal to the temperature coefficient of the bare FBG. In the strain test, one bare FBG (named as SFBG) and one electric resistance strain gauge are also installed on this glass plate, and both the length ends of the glass plate are clamped on the material testing machine. Under the tensile load provided by the material testing machine, the electric resistance strain gauge records the reference strain of the glass, and the wavelength of the SFBG is measured by the FBG demodulator. The initial wavelength of the SFBG is $1550.344 \mathrm{~nm}$. As illustrated in Fig. 1(b), the strain sensing coefficient of SFBG is $1.18 \mathrm{pm} / \mu \varepsilon$, which is also approximately equal to the strain coefficient of bare FBG. Both the strain and temperature tests express that the coefficient of thermal expansion and the elastic modulus of the bare FBG are almost equal to those of the common glass, which also hints that the FBG is suitable for the damage monitoring of the glass structures.

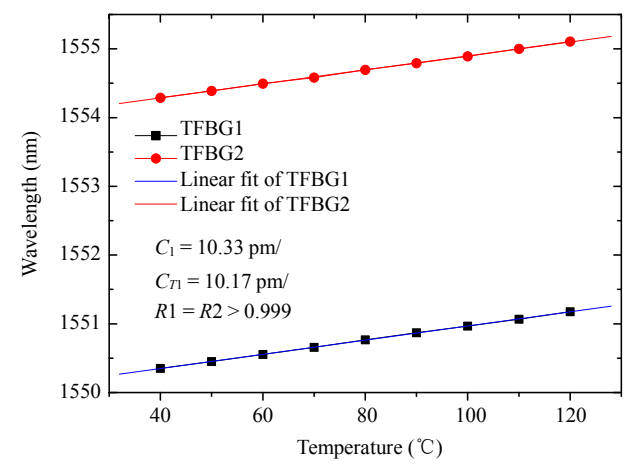

(a)

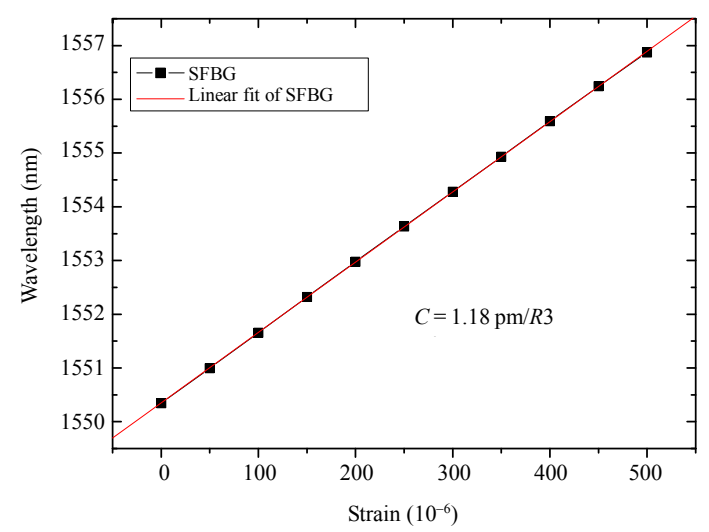

(b)

Fig. 1 Sensing calibration results of FBG installed on the glass: (a) temperature sensing calibration and (b) strain sensing calibration.

Furthermore, as illustrated in (2), there exists strain-temperature cross sensitivity for the FBG sensor. For the field applications, temperature compensation for strain measurement must be done 
[16, 17]. The straightforward approach for temperature compensation is to employ two independent FBG sensors with the first one subjected to strain and temperature and the second one isolated from strain, and the two FBG sensors are in the same temperature field. In this study, the test is done in the lab, and room temperature is remained basically unchanged during the whole test process, so temperature compensation for strain measurement is not considered.

\section{Damage test of glass panel based on FBG sensors}

\subsection{Experimental setup}

In order to validate the feasibility and effectiveness of the FBG monitoring method under dynamic and static loads, two tests are conducted, and the experimental setup is illustrated in Fig. 2. The first one is that the glass panel is applied a concentrated load at the centric position of the glass panel, and the other one is that the glass panel is applied an impact load at the centric position too. The impact load is produced by a force hammer, the concentrated static load is produced by several weights, and each weight is about $5 \mathrm{~kg}$.

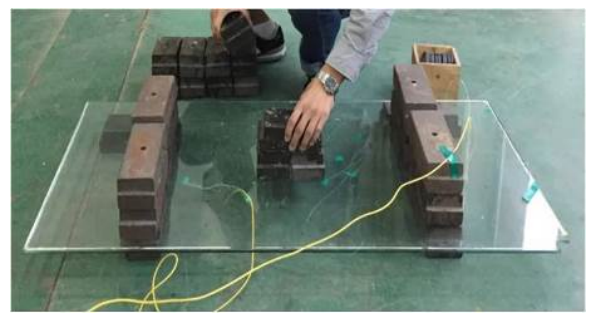

(a)

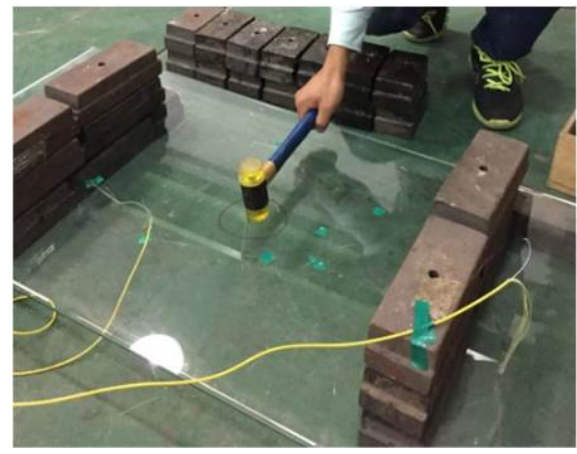

(b)

Fig. 2 Picture of experimental setup: (a) concentrated static load and (b) impact load.
Figure 3 shows the experimental setup of the damage test for one glass panel with the size of $1200 \mathrm{~mm} \times 600 \mathrm{~mm} \times 7 \mathrm{~mm}$, which is clamped at the two short edges by the weight, and the span is $800 \mathrm{~mm}$. Four bare FBG sensors are symmetrically installed on central position of the upper and lower surfaces of the glass panel, where FBG1 and FBG2 denote the FBG sensors installed on the upper surface of glass panel, and FBG3 and FBG4 denote the FBG sensors installed on the lower surface of glass panel. The FBG1 sensor is set perpendicular to the FBG2 sensor, and the FBG3 sensor is set perpendicular to the FBG4. The FBG2 and FBG4 measure the strain in the $x$ direction, and the $y$ direction. The initial FBG's wavelengths of FBG1 and $\mathrm{FBG} 2$ are $1547.897 \mathrm{~nm}$ and $1553.538 \mathrm{~nm}$, and those of FBG3 and FBG4 are $1532.373 \mathrm{~nm}$ and $1538.563 \mathrm{~nm}$, respectively. The four FBG sensors are connected in series to form one sensing circuit. By comparison with the FBG sensors, two resistance strain gages, named as RSG1 and RGS2, respectively, are installed on the central position of the upper and lower surfaces of the glass panel too, as shown in Fig. 3. In these tests, the Bragg wavelengths of the FBG sensors are collected by the

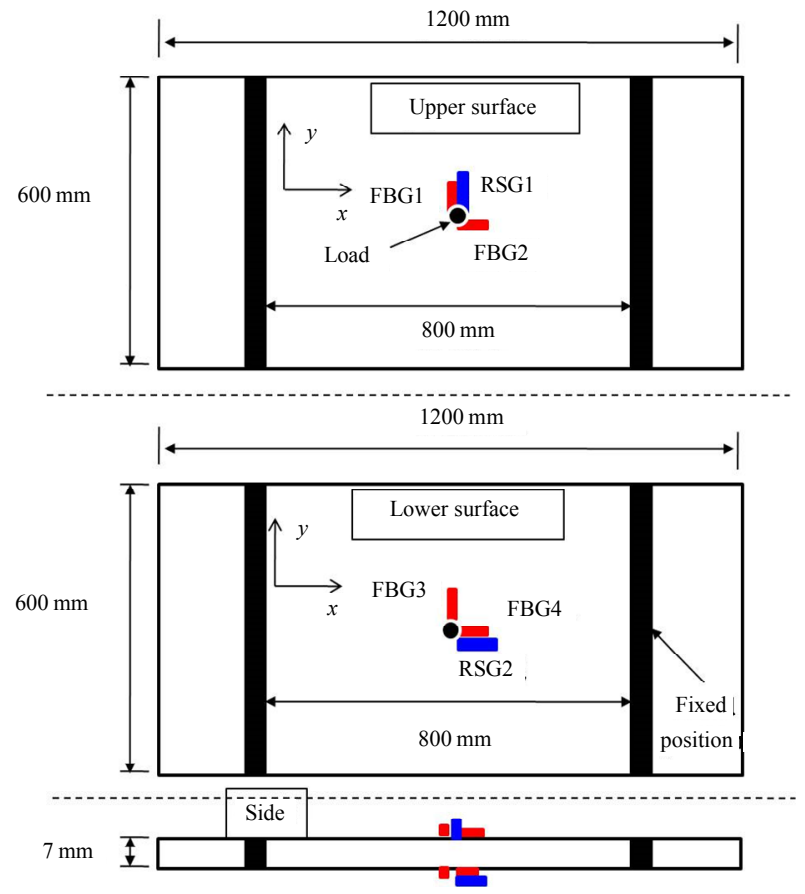

Fig. 3 Sensor layout on the glass panel. 
FBG demodulator produced by the Dalian Bo Ruixin Technology Co., Ltd. with the sampling frequency of $100 \mathrm{~Hz}$ and the measuring accuracy of $\pm 2 \mu \varepsilon$.

\subsection{Test results and analysis}

Figure 4 shows the finite element model of the glass panel, and the material properties of the glass panel are as follows: $E=75 \mathrm{GPa}, v=0.33$, $\rho=2.5 \mathrm{~g} / \mathrm{cm}^{3}$, and $P=40 \mathrm{MPa}$, where $E, v, \rho$, and $P$ are the elastic modulus, Poisson ratio, density, and tensile strength, respectively. The finite element model (FEM) includes one shell solid (SHELL181) and is modeled with 1426 nodes and 1350 elements. Figure 5 shows the results of the FEM analysis of the glass panel under a concentrated load of $10 \mathrm{~kg}$.

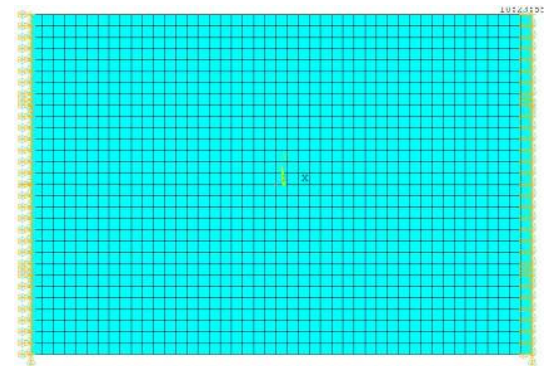

Fig. 4 Finite element modeling of the glass panel.

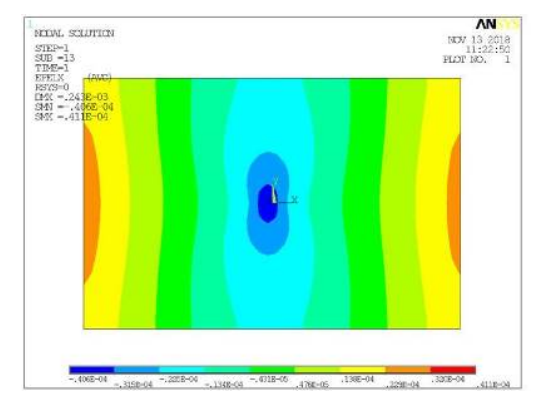

(a)

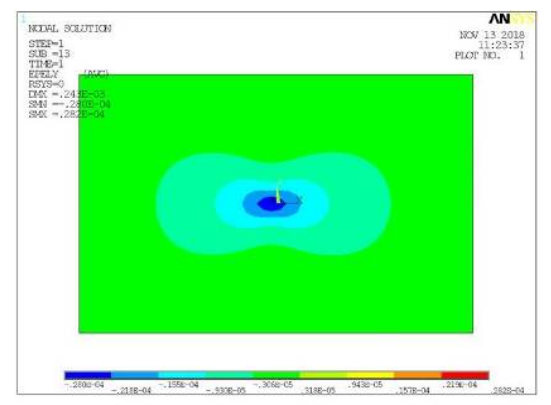

(b)

Fig. 5 Element results of glass panel under a concentrated load of $10 \mathrm{~kg}$ : (a) strain cloud diagraph in the $x$ direction and (b) strain cloud diagraph in the $y$ direction.

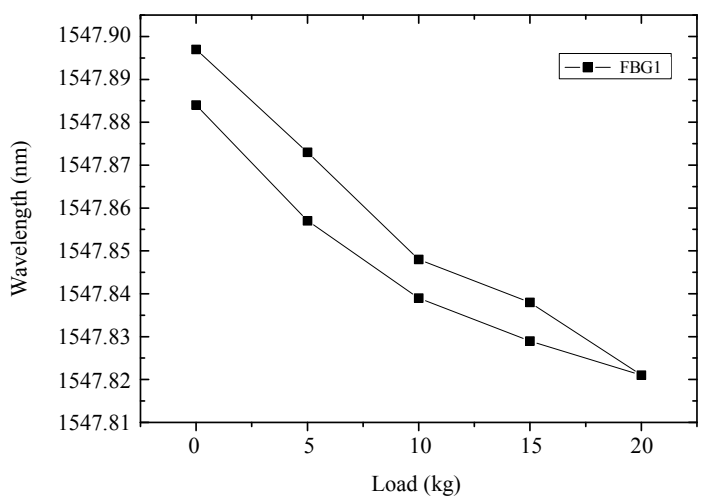

(a)

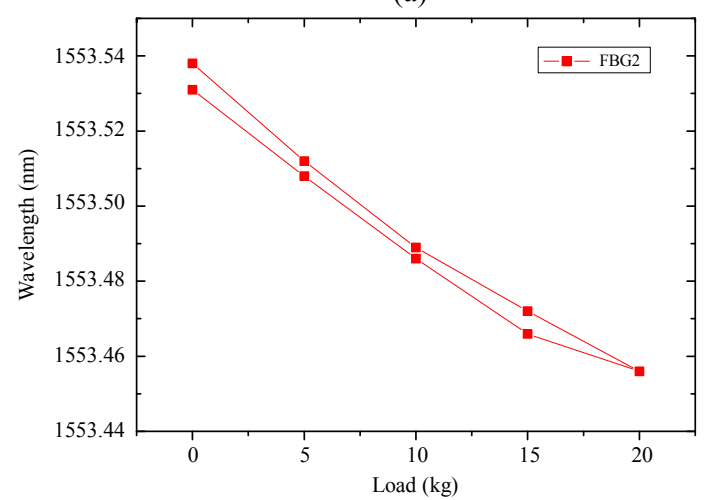

(b)

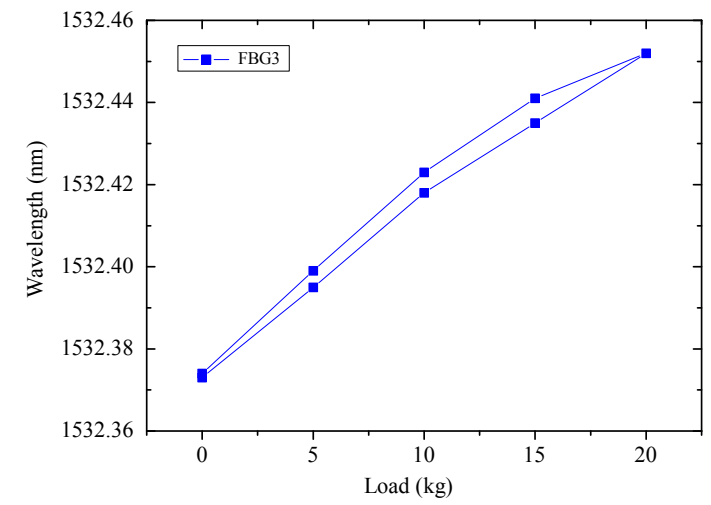

(c)

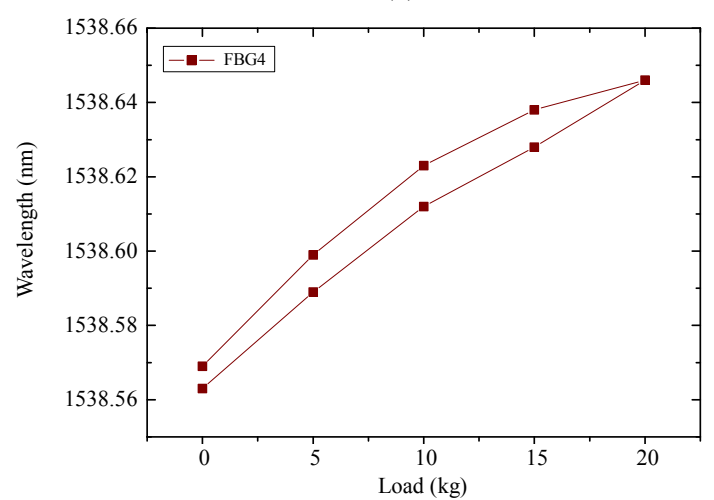

(d)

Fig. 6 Measured FBG's wavelengths under different levels of load (a) change of FBG1's wavelength, (b) change of FBG2's wavelength, (c) change of FBG3's wavelength, and (d) change of FBG4's wavelength. 
Figure 6 shows the wavelength shifts of the four FBG sensors installed at the upper and lower surfaces of glass panel under different levels of concentrated static loads. It can be seen from the figure that the measured wavelength data at the upper surface of glass panel decrease with an increase in load and those at the lower surface increase with an increase in load.

Figure 7 shows the strain data calculated from (2), measured by the two resistance strain gages and calculated from the FEM analysis. The strains measured by FBG sensors and resistance strain gages at the upper and lower surfaces of glass panel both exhibit anti-symmetric behavior as shown in this figure. Due to the different directions of constraint, the strains in the $x$ direction measured by FBG2 and FBG4 are slightly larger than those in the $y$ direction measured by FBG1 and FBG3 at each level of load. In Fig. 7, the strain data "FEM+X", "FEM-X", "FEM + Y", and "FEM-Y" denote the strain at the lower and upper surfaces in the $x$ direction and $y$ direction of the glass panel calculated by FEM analysis, respectively. The comparison among the strain data measured by the two resistance strain gages, those measured by the four FBG sensors, and those calculated from FEM analysis shows a favorable agreement as illustrated in Fig. 7. The reason that the strains obtained with the experiments are slightly different from those obtained with the FEM analysis is that the concentrated loading area on the glass panel in the experiment is larger than that in the FEM analysis. The strains measured by the FBG1 and FBG4 are nearly equal to those measured by the two resistance strain gages, and the maximum absolute strain errors between the FBG sensors and the resistance strain gages on the upper and lower surfaces of glass panel are about $5 \mu \varepsilon$, as shown in Fig. 8 . The static load test results show that the FBG sensors can effectively measure the glass panel's compression and tensile properties.

Figure 9 shows the wavelength time travel curves of the four FBG sensors under the impact load. It also can be seen that the wavelength data collected by FBG1 and FBG2 installed at the upper surface of the glass panel show compression behavior and those measured by the FBG3 and FBG4 installed at the lower position exhibit tensile behavior.

Figure 10 shows the strain time travel data measured by the two resistance strain gages and calculated from the four wavelength time travel curves as illustrated in Fig. 9. It can be seen that the maximum strain applied on the upper and lower surfaces of the glass panel are respectively $-90 \mu \varepsilon$ and $90 \mu \varepsilon$ happening in 19.3 second, and the strain time travel curves between the FBG sensors and the resistance strain gages have good consistency. It also can be seen that the strain curve of the upper surface and that of the lower surface of the glass panel show anti-symmetric behavior. The impact load test results show that both the FBG sensors and the resistance strain gages installed at the upper and lower surfaces can effectively monitor the dynamic deformation applied on the glass panel.

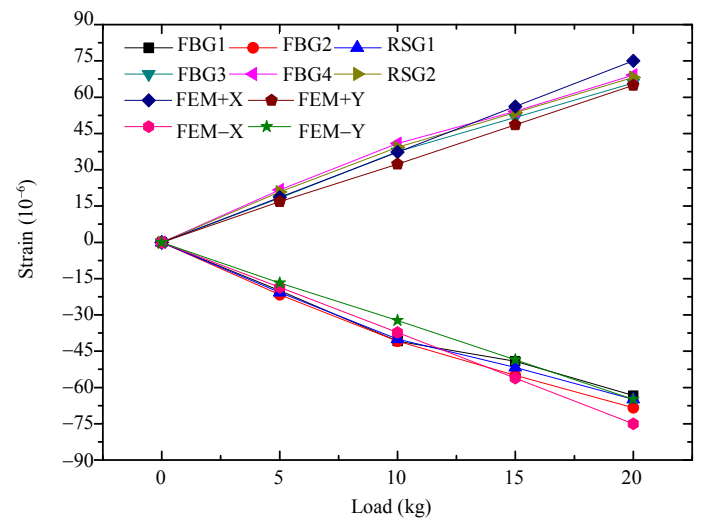

Fig. 7 Measured strain data by FBG sensors, resistance strain gages, and calculated from FEM analysis.

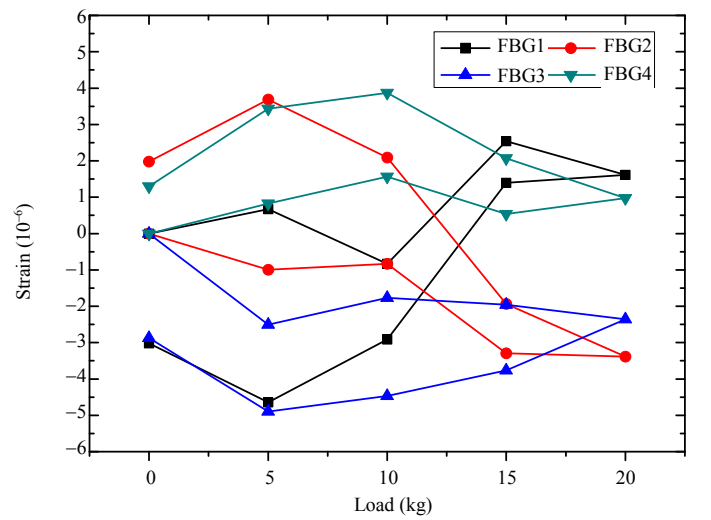

Fig. 8 Relative error between the FBG sensors and the resistance strain gages. 


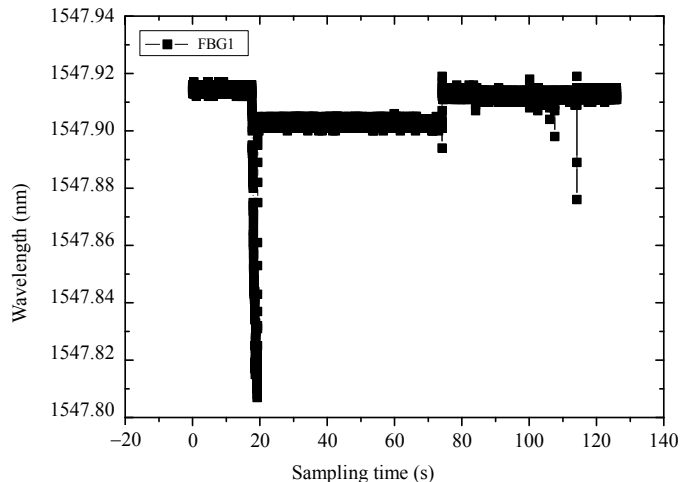

(a)

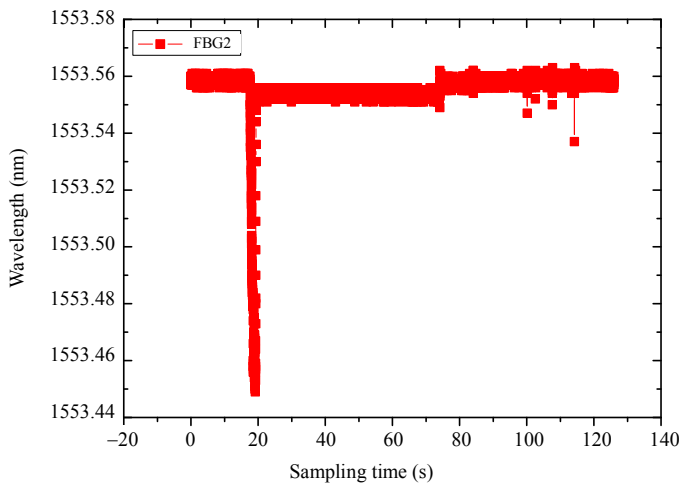

(b)

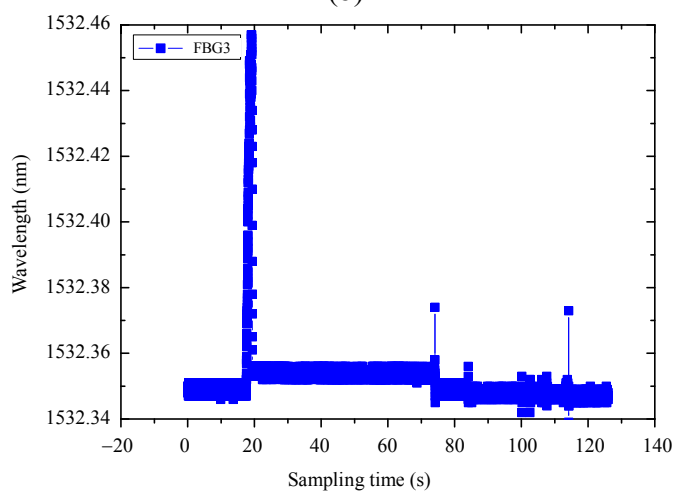

(c)

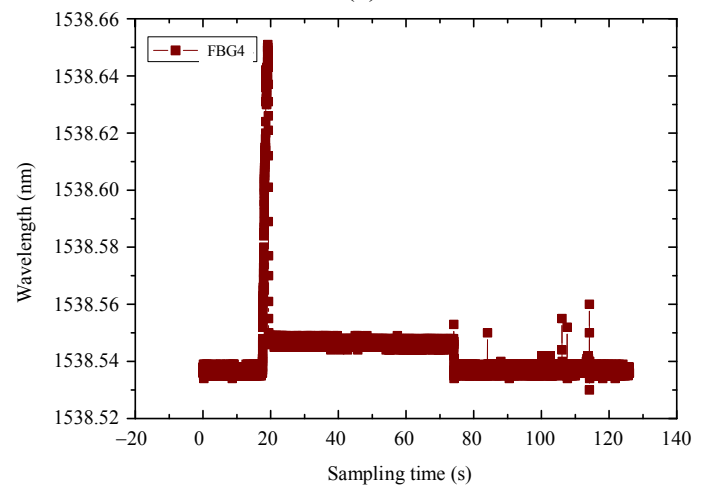

(d)

Fig. 9 Wavelength time travel curves of the four FBG sensors under impact load: (a) wavelength time travel curve of FBG1, (b) wavelength time travel curve of FBG2, (c) wavelength time travel curve of FBG3, and (d) wavelength time travel curve of FBG4.

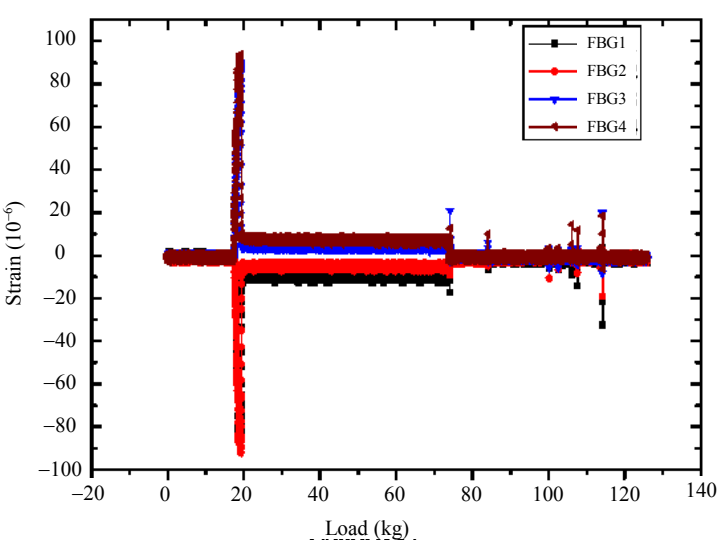

(a)

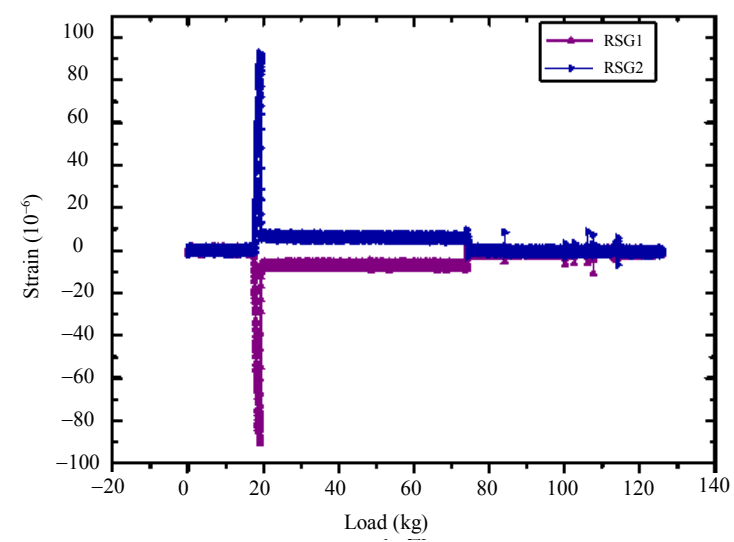

(b)

Fig. 10 Strain time travel curves under the impact load: (a) strain time travel curves measured by FBG sensors and (b) strain time travel curves measured by resistance strain gages.

Figure 11(a) shows the broken photo of the glass panel under a large load. It can be seen that the damage extends from the center to the periphery. Figure 11(b) shows the measured strain from the FBG sensors and the resistance strain gages during the whole damage process. The whole test process includes three parts: strain increasing stage, strain stationary stage, and strain descending stage. In the strain increasing stage, the maximum strains are about $180 \mu \varepsilon$ and $-180 \mu \varepsilon$ at the lower and upper surfaces of glass panel respectively under the load of $45 \mathrm{~kg}$. In the strain stationary stage, the load keeps $45 \mathrm{~kg}$ for about two minutes. Then, the damage in the glass panel occurs as the load increases and the glass panel is quickly broken. In the strain descending stage or the broken process of the glass panel, the first point at the strain descending stage is the damage initiation point on the glass, and the 
strains measured by the four FBG sensors turn small to zero; later, the strains turn large but the strain direction is reversed due to the stress redistribution. Finally, the sensors of FBG1, FBG2, and FBG4 are damaged, and the FBG3 is good. The final strain measured by FBG3 is about $0 \mu \varepsilon$. The data pictured in the Fig. 11(b) are drawn from the real-time strain data flow at intervals of one second in order to identify each deformation state of the glass panel. It also can be seen that the strain data from the resistance strain gages show a good agreement with those from the FBG sensors, and the two resistance strain gages are fully broken finally.
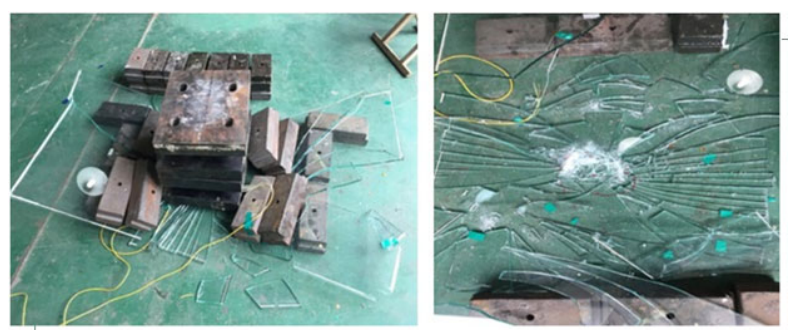

(a)

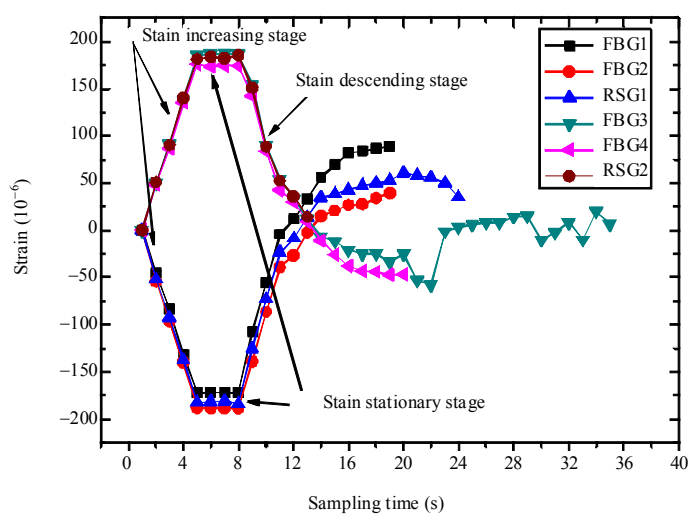

(b)

Fig. 11 Results of the damage test: (a) broken photo of the glass panel and (b) strain curve in the broken process.

\section{Conclusions and future work}

In this work, the small size FBG sensors have been applied to monitor the glass deformation. In order to validate the feasibility and effectiveness of the monitoring method, one common glass panel model is constructed and applied static and impact loads. A comparison among the measuring data from four FBG sensors, those collected from two resistance strain gages installed on the lower and upper surfaces of the glass panel, and those calculated from FEM analysis is done. Based on the test results, the following conclusions have been obtained: (a) the result obtained with experiments agrees with the element result, which hints that the FBG sensors can correctly monitor the compression and tensile deformation of the glass panel; (2) both the FBG sensors and the resistance strain gages can monitor the damage information in real time, and the impact load test results further show that the FBG sensor is adaptive to dynamic monitoring of glass structures.

Although the initial study has proved the FBG sensor's feasibility to monitor deformation of glass structures, the diameter of the bare FBG is too small to influence the beauty of the glass structure. There is still some work to be studied in future: (a) to ensure the survival of the FBG sensor and without affecting the beautiful appearance of the glass structure, sensor layout method should be developed; (2) the safety evaluation method for glass structures will be studied by using the deformation measured by FBG sensors.

\section{Acknowledgment}

The authors are grateful for the financial support from the National Natural Science Foundation of China (NSFC) under Grant Nos. 61675102 and 61875027, and the National Key Research and Development Program of China under Grant No. 2016 YFC0701107.

Open Access This article is distributed under the terms of the Creative Commons Attribution 4.0 International License (http://creativecommons.org/licenses/by/4.0/), which permits unrestricted use, distribution, and reproduction in any medium, provided you give appropriate credit to the original author(s) and the source, provide a link to the Creative Commons license, and indicate if changes were made.

\section{References}

[1] V. Beatini and G. R. Carfagni, "Glass as a material," 
Materia, 2011, 69: 36-43.

[2] B. Massimo, B. Luigi, R. C. Gianni, and S. Walter, "Safety factors for the structural design of glass," Construction and Building Materials, 2014, 55: 114-127.

[3] W. G. Guo and F. F. Shi, "Deformation and failure behavior of MDYB-3 oriented PMMA glass under different loading conditions," Acta Aeronautica et Astronautica Sinica, 2008, 29(6): 1517-1525.

[4] H. Y. Wu, G. Ma, and Y. M. Xia, "Experimental study of tensile properties of PMMA at intermediate strain rate," Master of Letters, 2004, 58(29): 3681-3685.

[5] G. S. Guan, S. H. Wang, and F. Y. Cheng, "Compression failure and mechanics behavior of PMMA under different loading strain rates," Journal of Aeronautical Materials, 2012, 32(6): 96-101.

[6] L. Biolzi, S. Cattaneo, and G. Rosati, "Progressive damage and fracture of laminated glass beams," Construction and Building Materials, 2010, 24(6): 77-84.

[7] W. Roundi, A. E. Mahi, A. E. Gharad, and J. L. Rebiere, "Acoustic emission monitoring of damage progression in glass/epoxy composites during static and fatigue tensile tests," Applied Acoustics, 2018, 132: $124-134$.

[8] Y. Kuang, Y. X. Guo, L. Xiong, and W. L. Liu, "Packaging and temperature compensation of fiber Bragg grating for strain sensing: a survey," Photonic Sensors, 2018, 8(4): 320-331.

[9] T. H. T. Chan, L. Yu, H. Y. Tam, Y.Q. Ni, S. Y. Liu, W. H. Chung, et al., "Fiber Bragg grating sensors for structural health monitoring of Tsing Ma bridge: background and experimental observation," Engineering Structures, 2006, 28(5): 648-659.
[10] K. Schroeder, W. Ecke, J. Apitz, and E. Lembke, “A fiber Bragg grating sensor system nonitors operational load in a wind turbin rotor blade," Measurement Science and Technology, 2006, 17(5): 1167-1172.

[11] P. Schubel, R. Umer, and E. K. G. Boateng, "Modeling heat transfer through an FBG optical fibre," Composites Part A: Applied Science and Manufacturing, 2018, 109: 184-196.

[12] M. A. Tarawneh, Y. Huang, P. Lu, and D. Tolliver, "Vehicle classification system using in-pavement fiber Bragg grating sensors," IEEE Sensors Journal, 2018, 18(7): 2807-2815.

[13] Z. Zhou, J. P. He, K. Yan, and J. P. Ou, "Fiber-reinforced polymer-packaged optical fiber sensors based on Brillouin optical time-domain analysis," Optical Engineering, 2008, 47(1): 014401-1-014401-10.

[14] K. O. Hill, B. Malo, F. Bilodeau, D. C. Johnson, and J. Albert, "Bragg grating fabricated in monomode photosensitive optical fiber by UV exposure through a phase mask," Applied Physics Letters, 1993, 62(10): 1035-1037.

[15] S. I. Takeda, J. Koyanagi, S. Utsunomiya, Y. Kinoshita, Y. Arao, and H. Kawada, "Monitoring of internal residual strain changes in CFRP using FBG sensors," SPIE, 2010, 7522: 75223N-1-75223N-8.

[16] J. P. He, Z. Zhou, and J. P. Ou, "Simultaneous measurement of strain and temperature using a hybrid local and distributed optical fiber sensing system," Measurement, 2014, 47: 698-706.

[17] S. H. Zhang, J. P. He, and Z. Zhou, "Temperature sensing characteristics of FBG under different level stress and boundary conditions," Pacific Science Review, 2011, 13(3): 222-226. 